\title{
A construção da Constituição de 1988 aos olhos da imprensa
}

\section{The construction of the 1988 Constitution in the eyes of the press}

\section{Cândida Emília Borges Lemos}

Doutora em História pela Faculdade de Letras da Universidade do Porto, Portugal; Mestre em Ciência Política pela Universidade Federal de Minas Gerais (1988) e Professora do Instituto de Comunicação e Artes do Centro Universitário UNA, Belo Horizonte. <candida.lemos@prof.una.br>

\section{RESUMO}

\begin{abstract}
Este artigo analisa o desempenho jornalístico das revistas semanais brasileiras Istoé e Veja no período da Assembleia Constituinte de 1987/88 no Brasil. A imprensa é concebida como integrante da cultura política e social de um país. Portanto, é geradora de opiniões e visões de mundo, porém, ao mesmo tempo, reflete a dinâmica social e política. É a síntese de um determinado tempo histórico e contribui para a formação desse mesmo momento, ao criar referenciais ideológicos e valorativos na opinião pública. No período em tela, as discussões travadas na Assembleia Nacional Constituinte refletiam as forças políticas que atuavam na trama social em busca para se confeccionar um articulado constitucional. Neste contexto, cada votação refletia a disputa social, para além dos partidos políticos, no jogo de interesses de grupos e segmentos sociais e suas ideologias.
\end{abstract}

Palavras-chave: Revistas. Assembleia Constituinte. Jornalismo.

\begin{abstract}
This paper examines the performance of the Brazilian weekly magazines Istoé and Veja in the period of Constituent Assembly in 1987-88. The press is designed as part of the political and social culture of a country. From this perspective, is giving rise to opinions and views of the world, but at the same time, reflects the social and political dynamics. So is the synthesis of a particular historical time, but also contributes to the formation of that historic moment, to create benchmarks of ideologies and attitudes in public opinion. In the period in question, the discussions in the Constituent National Assembly reflected the political forces that worked in the social fabric search in order to manufacture a constitutional articulated. In this context, each vote reflected the social dispute, apart from political parties, in the game of group interests and social groups and their ideologies.
\end{abstract}

Keywords: Magazines. Constituent Assembly. Journalism.

\section{Introdução}

Ao analisar fatos, comportamentos, conteúdos e valores veiculados na imprensa no processo de elaboração da Constituição do Brasil (1987/88), entende-se que esses registros e mensagens dos media se inscrevem como fenômenos culturais, ideológicos e históricos, nos quais os meios de comunicação de massa são integrantes, como formadores e orientadores da opinião pública.

Como parte da memória das culturas políticas e como instituição que registra os fatos históricos, a imprensa o faz ao definir enfoques, hierarquia de importância dos acontecimentos, enfim, estabelece o que será notícia, o que 
deverá ser registrado ou esquecido. A imprensa faz um recorte da realidade, por meio do qual emite opiniões e ideias.

O objetivo deste artigo é contribuir para a compreensão do desempenho institucional dos media e de sua inserção para a formação de vontades e de tendências políticas na construção e na consolidação das esferas democráticas da sociedade brasileira.

Delimitam-se como estudo de caso as revistas semanais Istoé (IE) e Veja (VE), as mais conceituadas no país à época da Assembleia Nacional Constituinte (ANC). Cabe dizer que o trabalho jornalístico das revistas é prescrito em determinado momento histórico, portanto, não diz respeito à ação jornalística das semanárias nos dias de hoje.

A promulgação do novo texto constitucional deu-se em 5 de outubro de 1988 (Veja, n. 1048, 12/10/1988). Neste trabalho foram escolhidos alguns temas considerados emblemáticos que envolveram a elaboração da Carta Constitucional, tais como a forma de governo e a duração do mandato do então presidente da República, José Sarney.

A revista Veja, da Editora Abril, de nítida inspiração das revistas norteamericanas Time e Newsweek, propunha fazer um jornalismo investigativo e analítico dos fatos. Foi lançada durante o período mais autoritário da Ditadura Militar Brasileira, 1968 (Veja, n. 1, 11/9/1968). Assim, nasceu sob a marca da censura governamental e foi um de seus destacados alvos.

Por sua vez, Istoé nasceu no processo de abertura política (IstoÉ, n. 1, 1\%/5/1976), livre, portanto, da censura ostensiva governamental, e buscou apresentar aos seus leitores uma visão mais à esquerda do que Veja, mas com semelhantes propostas jornalísticas: a de pluralidade ideológica e a de realização de um jornalismo interpretativo. A revista pertenceu a vários grupos empresariais, desde a sua origem.

Para tanto, houve pesquisas aos originais das revistas, realizadas na Biblioteca Pública Estadual Luiz de Bessa, em Belo Horizonte, Minas Gerais, Brasil. Busca-se aferir em que medida estas revistas refletiram com profundidade, com pluralidade e fidelidade os debates travados pelos diversos partidos presentes na ANC. Foram entrevistados os jornalistas Paulo Moreira Leite e Ariosto Teixeira, que à época da ANC participaram ativamente das coberturas dos trabalhos constituintes nas revistas Veja e Istoé, respectivamente. Também foi entrevistado o deputado constituinte Virgílio Guimarães, da bancada do Partido dos Trabalhadores (PT). 


\section{Pauta regular e centro do noticiário}

A participação nas urnas, nas primeiras eleições livres após o fim da ditadura militar, em 1986, foi de $60 \%$ do universo eleitoral, que votou em algum candidato à Câmara dos Deputados, sem contar os brancos e nulos (Kinzo, 2004 , p. 30). A ANC era legitimada pela opinião pública e pela mídia, haja vista a ampla cobertura que recebeu da imprensa. Pesquisa do Instituto Brasileiro de Opinião Pública e Estatística (Ibope) aferiu que os trabalhos dos parlamentares eram bem avaliados pelos brasileiros entrevistados, já que $53 \%$ das pessoas ouvidas consideravam a atividade dos constituintes oscilante entre regular e ótima. Entretanto, apenas $28 \%$ dos entrevistados confiavam no governo Sarney, enquanto 64\% desconfiavam (Veja, n. 1037, p. 32, 20/7/88).

A ANC teve uma divulgação cotidiana e farta. De acordo com Regimento Interno, foi instituído o Diário da Constituinte, programa de rádio e TV, com duração de cinco minutos, que foi ao ar, durante toda a vigência da ANC, de segunda a sexta-feira, duas vezes ao dia, apresentado por todas as emissoras de rádio e TV em horários diferentes, definidos por cada uma delas, desde que fosse no horário nobre (DANC, 1987).

O programa, produzido pela estatal Empresa Brasileira de Notícias, estreou em abril de 1987 e estendeu-se até a aprovação da Carta. No seu mês de estreia, o programa pecou pela má qualidade das imagens e das reportagens. O próprio presidente da ANC, Deputado Ulysses Guimarães, admitia que o programa não estivesse bem: “Vamos melhorá-lo" (Veja, n. 974, p. 117, 6/5/87). Porém, a qualidade do Diário da Constituinte eletrônico melhorou e foi uma importante ferramenta para difundir os trabalhos da ANC, para que o cidadão pudesse se informar acerca dos trabalhos no Congresso.

O ex-deputado Federal Virgílio Guimarães, então em sua primeira legislatura e um dos 16 deputados do Partido dos Trabalhadores (PT), recordase do Diário Constituinte: "Foi muito forte para o acesso da população ao que se era discutido e votado na $A C$, além do mais houve um equilíbrio de espaço entre os partidos nas coberturas. Foi fundamental". (Guimarães, 2008).

Além do tempo de antena livre em todas as emissoras de TV e rádio, de norte a sul do Brasil, que a ANC se beneficiou na mídia - emissoras de rádio e TV, jornais diários e revistas semanais -, a atividade era pauta regular e recheava os noticiários.

O país vivia um momento de debate profundo e a imprensa participava ativamente dele. Na cobertura jornalística da ANC, "foi uma efervescência geral, e a imprensa também vivia o seu momento mágico" (Guimarães, 2008) 
Assim, a cobertura estava muito além do que os donos da mídia queriam ou não divulgar, e "o papel do jornalista, independente de qual veículo trabalhasse, era fundamental", lembra Guimarães (2008). As direções dos veículos não tinham um controle total sobre o que era veiculado, pois "havia muitos jornalistas que eram de esquerda, então era muito difícil o controle de todo mundo" (Guimarães, 2008).

Para ele, a esquerda, assim, tinha espaço nos meios informativos. $\mathrm{Na}$ opinião do parlamentar, no período em tela, o segmento das revistas semanais era o mais fechado às propostas dos deputados da esquerda, mas, mesmo assim, acabava por divulgá-las. Entretanto, "os jornais diários e as rádios eram os segmentos mais abertos". Todavia, a TV era mais fechada, em especial a TV Globo. “Depois da campanha das 'Diretas Já!', movimento que passou quase despercebido pela maior rede de TV do país, o que levou à perda de audiência da emissora; na AC, ela melhorou um pouco, embora haja restrições quanto à sua cobertura", avalia Guimarães (2008).

Nos estudos acerca da democracia, é destacada a questão da liberdade de informação, que, por conseguinte, desdobra-se nas liberdades de opinião e de expressão. Na sociedade poliárquica de Dahl, entre os requisitos da democracia, adquire relevo a existência de fontes alternativas e independentes de informação para que o cidadão tenha a compreensão esclarecida. Questiona Dahl (2001, p. 111): "Como os cidadãos podem adquirir a informação de que precisam para entender questões se o governo controla todas as fontes de informação?" E vai além:

Se apenas um grupo goza do monopólio de fornecer a informação? [...] Como poderiam os cidadãos participar realmente da vida política se toda a informação que pudessem adquirir fosse proporcionada por uma única fonte. [...] um único partido, uma facção ou um único interesse? (Dahl, 2001, p. 111).

A liberdade de informação engloba a liberdade para se adquirir a informação, de ter-se acesso às fontes. Portanto, aquela se situa além do regime político adotado, diz respeito a um bem público, que "caracteriza o contexto social geral e é em si mesma respaldada por um sistema democrático legal" (O'Donnel, 1999, p. 622).

O país conviveu com a censura de forma direta e intensiva. Havia uma geração de jornalistas que esteve nas redações no período democrático que abarcou de 1946 a 1964. Além disso, a censura no Brasil não foi exercida com a mesma intensidade durante os 21 anos de ditadura. O Governo 
Médici, sobremaneira, foi quando ela foi exercida com mais rigor. Mas havia contramarchas, pois em plena política de abertura do Governo Geisel (19741979), o Ministro da Justiça, Armando Falcão, baixava a Portaria n 427/77, na qual instituía a censura prévia às publicações vindas do exterior (Veja, n. 457, 8/6/77).

O jornalista Moreira Leite ingressou na profissão em 1969, no Jornal da Tarde, em São Paulo. Ele acredita que a forma de se fazer o jornalismo não mudou muito na ditadura e no período de transição democrática, porém houve uma modificação na forma de pensar dos jornalistas:

\begin{abstract}
A grande diferença é que a nova geração entrou nas redações após passar por um batismo político nas universidades. Era uma geração que pegou a saída da ditadura, mais politizada, que havia feito uma luta vitoriosa pela anistia, no apoio ao movimento operário, pelas diretas-já, pela reconstrução de entidades estudantis. Isso foi se refletir nas conversas, pautas e na sensibilidade dos repórteres, redatores e mais tarde editores. Eu acho que a cobertura política daquele período reflete isso (Leite, 2008).
\end{abstract}

Durante a transição democrática, não houve uma preocupação latente em mudar as leis que regiam a imprensa. Na Constituição de 1988, o artigo $5^{\circ}$ reza sobre a livre manifestação e a liberdade de pensamento, a expressão da atividade intelectual, científica e de comunicação, independente de censura ou licença. Especificamente à Comunicação Social, os artigos 220 a 224, que abrigados no Título VII do Capítulo V, proclamam a extinção formal da censura, a comunicação coletiva, o direito de respostas e o dever de informar e ser informado (Brasil, 1988).

Quando o tema em pauta é a imprensa, logo surge uma velha polêmica dos estudiosos da mídia: a imparcialidade dos meios versus as opiniões acerca de fatos por quem os processa em escala industrial, a construção da notícia. A imparcialidade não existe na práxis jornalística, pois ao escolher a divulgação de um determinado fato e transformá-lo em notícia, inserem-se critérios técnicos como também valores culturais, ideológicos e políticos.

Regida por normas próprias de noticiabilidade e objetividade, a imprensa busca definir em seu dia a dia o que deve ou não se tornar notícia. Na linguagem jornalística, trata-se do newsjudement:

A invocação do news judgement (perspicácia profissional) é uma atitude inerentemente defensiva, pois o newsjudgement é a capacidade de escolher 'objectivamente' de entre fatos concorrentes 
para decidir quais os'fatos'que são mais'importantes'ou'interessantes'. Importante e interessante denotam conteúdo. Portanto, ao discutir a estruturação da informação, o jornalista deve relatar as suas noções de conteúdo 'importante' ou 'interessantes' (Tuchman, 1993, p. 83).

Em consequência desse conceito, é importante tentar distinguir os fios tênues existentes entre fatos e opiniões. Os primeiros dizem respeito a eventos de base empírica e só passam a existir se forem publicizados. Já as opiniões dizem respeito a interesses e a paixões, mesclam o racional e o irracional. A própria História comprova que os fatos para existirem como tais precisam ser recortados e interpretados, para depois serem inseridos na construção histórica de uma determinada época de um determinado lugar.

Arendt questiona: "Os fatos realmente existem, independentes de opinião e interpretação?" (Arendt, 1979, p. 296). Na linha divisória entre fato e opinião, a autora adverte que, por mais que o narrador tenha a sua adequação dos fatos à História e à forma narrativa escolhida, isto"não pode servir como uma justificação para apagar as linhas divisórias entre fato, opinião e interpretação, ou como uma desculpa para o historiador manipular os fatos a seu bel-prazer" (Arendt, 1979, p. 296).

Para o jornalista Moreira Leite, "informar corretamente os fatos já é uma tarefa muito difícil" (Leite, 2008). Sem dúvida informar corretamente os fatos, sem distorcê-los, é a primeira tarefa da imprensa, pois é neste ponto que ela transmite à sociedade o que estaria invisível. Tal discussão remete à noção de verdade e sua manifestação na esfera pública. Muitas vezes, a verdade tornase um "estorvo", pois "pretende peremptoriamente ser reconhecida e proscreve o debate" (Arendt, 1979, p. 300), que é a própria razão da política. Portanto, a pluralidade de opiniões é fundamental para que se formem opiniões e ideias a respeito de fatos. Nessa perspectiva, os meios informativos em análise foram palco privilegiado onde as lutas políticas e ideológicas se expressaram com contundência.

Os textos jornalísticos são polifônicos, pois neles estão implícitas ou explicitamente várias vozes, de diferentes procedências, apresentadas de diversas formas textuais. A polifonia não necessita, exclusivamente, da presença de um intertexto, cuja fonte é citada, portanto, "exige apenas que se representem, encenem, em dado texto, perspectivas ou pontos de vista de enunciadores diferentes" (Koch, 2006, p.154).

Nesta direção, situa-se a metáfora que define a polifonia como um "coro de vozes". Na polifonia, relativo à encenação dentro de um texto, os enunciadores podem ser reais ou virtuais, pois estes "não precisam servir-se, necessariamente, 
de textos efetivamente existentes" para compor o jogo de cena da linguagem (Koch, 2006, p.154).

Nojornalismo, a polifonia explícita é utilizada para se darmais credibilidade ao que está escrito. São as diferentes vozes que apontam à existência de um jornalismo plural e que retrata os dissensos sobre determinada temática. Porém, é importante frisar o termo'mais credibilidade', pois, por si, o discurso jornalístico já é "antecipadamente legitimado, uma vez que foi o próprio leitor que o comprou" (Maingueneau, 2002, p. 40). Logo, ao leitor que assinava Veja ou Istoé, ele o fazia porque acreditava naquela publicação. Neste contrato implícito entre produtor e leitor de informação, a mídia procura sanar os desejos, as dúvidas, as curiosidades e as necessidades de seu leitor potencial. A publicação jornalística, assim, "procura apresentar-se como quem responde a demandas explícitas ou não, dos leitores" (Maingueneau, 2002, p. 40). Parte-se do pressuposto de que o jornalista é digno de confiança e que nos relata aquilo que efetivamente aconteceu, "fazemos fé na credibilidade da sua palavra" (Rodrigues, 1993, p. 32).

Ao introduzir a polifonia jornalística, os recursos usados são os discursos direto, indireto e híbrido, que buscam apresentar as diversas vozes a que recorre o texto. No discurso direto, o enunciador não se coloca responsável pela fala, ao criar um distanciamento entre o autor do texto e o declarante. Mais além, por meio do discurso direto, o autor cria autenticidade ao seu próprio texto, pois indica "que as palavras relatadas são aquelas realmente proferidas" e também se mostra ao leitor "objetivo e sério" (Maingueneau, 2002, p. 142). "Os jornalistas veem as citações de opiniões de outras pessoas como uma forma de prova suplementar. Ao inserir a opinião de alguém, eles acham que deixam de participar na notícia e deixam os 'factos falar"' (Tuchman, 1993, p. 81).

Já o discurso indireto possibilita que o texto jornalístico seja mais opinativo e responsabiliza diretamente o jornalista ou a direção da publicação sobre a frase citada, pois esta passa a ser a frase comentada.

As duas revistas utilizavam-se correntemente do discurso direto. Todavia, Veja e IstoÉ optavam, muitas vezes, em suas reportagens, pelo discurso híbrido - direto e indireto intercalados. O discurso direto, ao privilegiar a narrativa, consegue estabelecer ao leitor "uma relação mais imediata com o vivido, palavras próprias das pessoas, como se o leitor estivesse presente na situação" (Maingueneau, 2002, p.150). Já as formas híbridas procuram manter o mesmo jornalismo vivo e, concomitantemente, sem comprometer a publicação sobre o texto narrado. IstoÉ oferece bons exemplos do discurso híbrido, o mais usual na imprensa brasileira. $\mathrm{O}$ tema era a decisão da Constituinte acerca do direito dos índios à terra: "O que pode levar a reduções substanciais das atuais reservas, 
segundo Raoni, pois em carta aos constituintes [...]" (discurso indireto). E na mesma reportagem: "Esse artigo só vai prejudicar as comunidades indígenas', lamenta o cacique Raoni Metutire, dos Txucarramae" (discurso direto) (IstoÉ, v.1, n. 597, p. 22-23, 1/11/1988). Em resumo, não era a revista IstoÉ que disse ser o texto aprovado na ANC prejudicial à comunidade indígena, mas um representante desta comunidade.

Veja, por sua vez, optava pelo discurso direto e usava, com parcimônia, o híbrido e o indireto. Quando na ANC votou-se a anistia às dívidas até certo valor monetário dos microempresários, a esquerda votou com o centro e isolou alguns setores mais reacionários do Congresso. A revista usou o discurso direto para apresentar a reação dos grupos mais à direita. Colocou uma frase dita por Ronaldo Caiado, do grupo dos produtores rurais na ANC: "A esquerda, que se diz defensora das classes trabalhadoras, provou que é a verdadeira lobista dos banqueiros". E a revista arrematou a citação de Caiado: "Vingou-se ele" (Veja, n. 1034, p. 35, 6/6/88).

Tanto no discurso indireto quanto no direto, há os verbos que introduzem a fala citada ou comentada, os dicendi, os declarandi e os sentiendi. Logo, são, muitas vezes, por meios deles, que o narrador coloca os seus pontos de vista. "A inclusão pura e simples de apenas verbos discendi de sentido geral, como "disse ele", "perguntou ele", desacompanhados de orações ou adjuntos adverbais, só se justifica quando tem propósito esclarecedor. Fora disso, o diálogo torna enfadonho" (Garcia, 1999, p.134).

Os verbos introdutórios "não são neutros, mas trazem consigo um enfoque subjetivo" (Maingueneau, 2002, 144), pois é por meio deles que o leitor será levado a interpretar os fatos e o contexto em que eles estão circunscritos.

Em Istoé, a ênfase nos verbos sentiendi, colocados nos relatos em discurso direto, nas complexas negociações entre o governo e o Partido do Movimento Democrático Brasileiro (PMDB) acerca da Carta (Constituinte): "O deputado José Lourenço admitiu que 'nada é inegociável'" (IstoÉ, n. 982, p. 32, 11/7/88). Se Lourenço admitiu ceder em alguns aspectos, significava que aceitava negociar com reservas.

Veja utilizou o discurso direto para reportar a manifestação estudantil contrária ao aumento das mensalidades escolares: "Vamos mostrar a nossa disposição de luta', comemora Valmir Santos, 26 anos, presidente da União Nacional dos Estudantes (UNE), aluno de História da Universidade Federal do Pará e militante petista" (Veja, n. 1023, p. 22, 13/4/88).

Os títulos que abrem as notícias e os artigos são fundamentais na construção jornalística. São por meio deles que o leitor tem o primeiro contato 
com a notícia e, a partir daí, decidirá se continuará ou não ler o texto. O principal recurso para dar tensão no título é colocar verbos que expressem dinamicidade e ritmo na frase. Deve conter informações novas ao leitor potencial. Como busca trazer ao leitor a ideia de atualidade, geralmente utiliza-se o tempo presente do modo indicativo (Mesquita, 2003).

É marcante entre as revistas brasileiras a existência de um paratexto, localizado entre o título e o texto, conhecido no jargão jornalístico como "bigode". Ele explica o título e é uma instância intermediária, que permite situar no tempo e no espaço o discurso narrativo.

Os títulos de Veja e de IstoÉ, em geral, eram formados de frases nominais, sem verbo, portanto, curtos. Algumas vezes, só poderiam ser totalmente inteligíveis caso o leitor também lesse o paratexto: "O voto do cansaço", e continuava o paratexto: "Em alta velocidade, a Constituinte impôs uma jornada pesada aos parlamentares e já aprovou mais de $60 \%$ da nova carta de leis" (Veja, n. 2025, p. 20, 27/4/88). Tal título tende a valorizar os constituintes, pois se havia "cansaço" entre os parlamentares era porque eles trabalhavam muito, estavam em estado de fadiga. O paratexto reforça esta ideia de trabalho e dinamismo da ANC, ao introduzir os adjetivos alta para qualificar velocidade e pesada para qualificar a jornada. No contexto da época, a ANC sofria o ataque do Executivo Federal, que pretendia esvaziá-la. Veja reforçava a importância do Legislativo e buscava legitimar aquele Poder.

Quando se votou o articulado relativo à propriedade da terra, o título de IstoÉ fora nitidamente "contrário" à decisão tomada pela ANC: "Porteiras fechadas". Ou seja, fechada é uma derivação do verbo fechar, que tem como sinônimos impedir, tampar, colocar limites, ter fim. Por conseguinte, o paratexto completava tal ideia: "A UDR dá um nó na reforma agrária” (IstoÉ, n. 595, p. 21, 18/5/88).

Quando a ANC foi entrecortada pela instalação de uma Comissão Parlamentar de Inquérito (CPI) que visava a investigar supostos esquemas de corrupção no Governo Sarney, IstoÉ entrevistou um dos parlamentares integrantes da Comissão. Como em Veja (entrevista com o presidente da Shell), IstoÉ utilizou para o título uma frase também do entrevistado: "Sarney violou a lei". Seguido do paratexto: "Senador José Ignácio Ferreira, da CPI da Corrupção, diz que administração caótica e favorecimentos ilícitos podem levar o presidente da República a perder o mandato" (IstoÉ, n. 983, p. 4, 18/7/88). Ou

1 UDR - União Democrática Ruralista. 
seja, fazia do discurso do entrevistado a sua própria opinião. A revista estava em clara oposição ao Presidente.

Nas publicações em análise, as opiniões estão presentes nos títulos, de forma sutil, por intermédio da utilização de recursos linguísticos nem sempre percebíveis a um leitor mais desatento. Ao partir do princípio de que cada palavra escrita em um texto tem sua razão de ser para a formação do discurso jornalístico, os termos qualificadores dos substantivos e dos verbos são reveladores de intenções e valores. No decorrer do texto, o narrador retoma ou refere-se aos personagens e instituições, por meio de adjetivos, advérbios ou expressões que dão força argumentativa e valorativa à narrativa.

$\mathrm{Na}$ Constituinte, a vitória da forma presidencialista de governo, por 343 contra 213 votos, ocorreu na mais significativa votação da ANC, pois conseguiu que todos os 559 parlamentares estivessem em plenário, em um placar que reuniu governistas e parte da esquerda, PT e PDT (Partido Democrático Trabalhista). $\mathrm{Na}$ sequência, votou-se a duração do mandato dos futuros presidentes da República: 304 votos para os cinco anos e 223 para os quatro anos. Cabe lembrar que o mandato de Sarney só seria votado nas "Disposições Transitórias" da Constituição. Com a aprovação dos cinco anos para todos os presidentes vindouros, porém, abriu-se caminho para ele consolidar os almejados cinco anos de governo.

Duas edições anteriores, Veja analisava que a votação estava empatada: "Qual será a decisão, não se sabe, e é provável que a bancada vitoriosa não consiga livrar uma vantagem superior a quarenta votos num plenário de 559 parlamentares" (Veja, n. 1019, p. 20, 16/3/88). Aliás, a reportagem da revista, ao apresentarasvantagenscomparativasentrepresidencialismoeparlamentarismo, tende ao parlamentarismo como melhor forma de governo: "Emagrecido, mas não desossado, o presidente conserva na emenda de Egídio (parlamentarista) poderes suficientes para garantir equilíbrio e estabilidade ao sistema, como ocorre nos governos parlamentaristas europeus" (Veja, n. 1019, p. 23, 16/3/88). Ou seja, o parlamentarismo traria estabilidade e equilíbrio, palavras que eram de extrema significação na América Latina, que pretendia virar a página de períodos instáveis que levaram aos regimes autoritários anteriores. Quando abordava os possíveis desentendimentos que poderia haver entre Legislativo e o Presidente da República, a reportagem aferia que o Presidente poderia, em casos excepcionais, demitir o gabinete inteiro. Mas a revista ponderava que aquelas medidas extremas visavam a "criar mecanismos que permitam acomodações na estrutura política sempre que um impasse se avizinhe - o que no presidencialismo brasileiro tende a ser resolvido em situações mais críticas 
com o rompimento das instituições" (Veja, n. 1019, p. 23, 16/3/88). Ou seja, o rompimento poderia ser o próprio fechamento do Congresso ou qualquer medida autoritária. Visto assim, a reportagem tendia ao Parlamentarismo.

Entretanto, o editorial de Veja, na mesma edição (Veja, n. 1019, 16/3/88,), a "Carta ao leitor" colocava uma foto do ex-presidente João Goulart, ao lado do seu Primeiro-Ministro, Tancredo Neves, na época quando o Brasil experimentou a forma de gabinetes para solucionar a instabilidade política, em 1961. Na legenda, estava a principal mensagem: "O gabinete de 1961: fracasso". Ao final, o editorial arrematava tal mensagem: "[...] sistema que foi imposto com a mesma ligeireza em 1961 e que acabou no desastre que todos conhecem" (Veja, n. 1019, p. 19, 16/3/88), em alusão ao golpe militar de 1964 que derrubou Goulart. Para o editorial, o parlamentarismo seria a tentativa de enfraquecer os poderes de Sarney. Alertava aos leitores: "A Assembleia Nacional Constituinte está preparando um embuste. Este embuste se chama parlamentarismo" (Veja, n. 1019, p. 19, 16/3/88). Se o parlamentarismo no Brasil poderia ser sinônimo do substantivo embuste, este por sua vez seria sinônimo de mentira artificiosa.

Após a votação, cabe abordar alguns qualificadores utilizados por Veja. Afinam-se os discursos do editorial e da reportagem: "O presidencialismo venceu o parlamentarismo por uma diferença arrasadora" (Veja, n. 588, p. 44, 30/3/88). Para se justificar do prognóstico anterior, o de que as duas formas de governo disputavam voto a voto, com chances iguais de vitória, Veja tendeu a culpar suas fontes: "Nada haveria de surpreendente nesse resultado se, nas últimas semanas, os constituintes mais equilibrados não tivessem previsto uma disputa palmo a palmo" (Veja, n. 1021, p. 44, 30/3/88). Ou seja, a revista ouvira fontes equilibradas, mas elas se equivocaram.

O movimento em prol do parlamentarismo, mesclado pela defesa da diminuição do mandato do Governo Sarney para quatro anos, em que teve mais expressão o grupo de Mário Covas e Fernando Henrique Cardoso, é assim qualificado na reportagem de Veja (n. 1021, p. 44, 30/3/88): "Era uma idéia vistosa - mas, como os balões, cheia de ar"; "os teimosos quatroanistas"; e referindo-se ao Deputado Euclides Salgado do Partido Democrático Brasileiro do Paraná(PMDB/PR), daquele agrupamento de parlamentares: "comentou nocauteado". Sobre a vitória: "movimento vigoroso", "luminoso princípio da maioria", "maior vitória”. (Veja, n. 1021, p. 44, 30/3/88. E descartava a possibilidade de compra de votos dos constituintes pelo governo: "Pode-se contestar de muitas maneiras o resultado da votação, mas é um equívoco atribuí-lo, numa Constituinte de 559 pessoas, à compra maciça de parlamentares por favores do governo". Para Veja, Ulysses Guimarães, que tentara um acordo com o Palácio 
do Planalto em torno de um parlamentarismo com cinco anos para o governo Sarney, saiu "chamuscado" do combate. E o presidente Sarney, no meio da polêmica, para um amigo "queixou-se amargurado". (Veja, n. 1021, p. 44, $30 / 3 / 88$,)

O colunista de IstoÉ José Antonio Severo, no entanto, mesmo que escrevesse para uma publicação nitidamente defensora do parlamentarista, acertava o alvo: "Há ainda o impulso favorável ao presidente com a entrada em cena de um reforço temido e respeitado, o ministro Thales Ramalho" (IstoÉ, n. 586 , p. 28, 16/3/88). Ramalho era ministro do Tribunal de Contas, mas foi ser um dos assessores de Sarney, já que desfrutava a amizade de Ulysses Guimarães e poderia mediar os conflitos entre o governo e o presidente da Constituinte. Porém, na reportagem que forneceu uma panorâmica sobre a votação que se realizou seis dias depois, IstoÉ (v. 1, n. 586, 16/3/88) duvidava da possibilidade de vingar um eventual acordo entre Sarney, Ulisses e os militares, pelo qual seriam cinco anos com parlamentarismo, pelas mãos de Ramalho: “Uma negociação que, com o efeito de uma poção mágica, acomodaria os interesses de Sarney, de Ulysses e da caserna" (IstoÉ, n. 586, p. 36, 16/3/88). Ao mesmo tempo, IstoÉ acreditava que o plenário estava "rigorosamente dividido, a um ponto que nenhum dos lados arrisca qualquer previsão" (IstoÉ, n. 586, p. 36, 16/3/88)

Após a votação, ao contrário de Veja, IstoÉ tributou a vitória do presidencialismo às manobras palacianas. Ao fato de o PT e o PDT terem votado pelo presidencialismo, a revista pontuou: "Composição impensável" (IstoÉ, n. 588, p. 20, 30/3/88). Sobre o deputado petista José Genuíno, que fora preso quando participou da luta camponesa em Goiás, no início dos anos 1970, Istoé ironizou o militante esquerdista: "Com a convicção do ex-guerrilheiro de uma estrela José Genuíno" (Istoé, n. 588, p. 20, 30/3/88). Para a revista, a vitória presidencialista fora alcançada em função de: "pesada pressão", "munição suficiente", "jogo pesado", "parlamentares duramente manobrados", "Sarney influiu decisivamente", "vistosa exibição de forças". Mais expressivo ainda era um dos títulos: "Rolo compressor" (IstoÉ, n. 588, p. 20-30, 30/3/88). Tais expressões trazem a força dos advérbios e adjetivos, que evidenciam o caráter opinativo do texto.

\section{Conclusões}

Em Veja e IstoÉ, o falar "em nome do público" era evidente apenas no editorial, no qual este se colocava como defensor da opinião do público, de 
representá-lo (Hall e outros,1993). Cada publicação, ao criar sua forma de se comunicar com seu público, transmite o consenso de valores que possui e aos quais o público leitor o legitima.

IstoÉ marcou pela irregularidade de sua cobertura ao Congresso, preferindo enfatizar os duros momentos econômicos que o país vivera. Sobrepondo a economia à política, sem perceber que, por mais que as duas esferas estejam entrelaçadas, elas têm formas próprias de operar e uma não é reflexo da outra, mas as se mesclam.

Cabe ressaltar que a fusão de IstoÉ com a revista Senhor, e a venda acionária do Grupo Gazeta Mercantil à Editora Três, em julho de 1988, foram dramáticas aos profissionais que lá trabalhavam, o que prejudicou sobremaneira a cobertura da ANC na "reta final das votações". Ariosto Teixeira recorda aqueles momentos: "Quase toda a equipe foi demitida" (Teixeira, 2008).

Veja, de forma geral, manteve a mesma postura desde o início até o final dos trabalhos. Procurou informar, desvendar os bastidores do poder, trazer as tramas. Deu ouvido às clivagens ideológicas, porém deixava claro o seu ponto de vista em cada ocasião em que um tema era debatido na ANC.

\section{Referências}

ARENDT, Hannah. Entre o passado e o futuro. 2 ed. São Paulo: Perspectiva, 1979.

BRASIL. Constituição (1988). Constituição da República Federativa do Brasil, 1988. Brasília: Senado Federal, Centro Gráfico, 1988. 292 p.

DAHL, Robert. Sobre a Democracia. Brasília: Editora UnB, 2001.

DANC - Diário da Assembleia Nacional Constituinte. Brasília: Câmara dos Deputados, n.15(15/2/87). Disponível em: <http://imagem.camara.gov.br>. Acesso em: 20 set. 2008 .

GARCIA, Othon. Comunicação em prosa moderna. 17. ed. Rio de Janeiro: Ed. FGV, 1999.

GUIMARÃES, Virgílio. Entrevista concedida à autora deste trabalho. Belo Horizonte (MG), 2008.

HALL, Stuart. e outros. A produção social das notícias: o mugging nos media. In: TRAQUINA, Nelson. (org.). Jornalismo: Questões, teorias e 'estórias'. 1. ed. Lisboa: Vega,1993, p. 224-248.

KINZO, Maria D'alva. Partidos, eleições e democracia no Brasil pós-1985. In: Revista brasileira de Ciências Sociais. v.19, n. 54, 2004. p. 23-40. 
KOCH, Ingedore. Introdução à linguística textual. São Paulo: Martins Fontes, 2006.

LEI DE IMPRENSA - suspensão de artigos. Informativo do Controle Apoio Operacional das Promotorias criminais, do Júri e de execuções de pena. n. 77, 2008.

LEITE, Paulo. Moreira. Entrevista concedida à autora deste trabalho. Washington D.C., 2008

MAINGUENEAU, Dominique. Análise de textos de comunicação. 2. ed. São Paulo: Cortez, 2002.

MESQUITA, Mário. O quarto equívoco - o poder dos media na sociedade contemporânea. Coimbra, Edições Minerva, 2003.

O'DONNEL, Guillermo. Teoria Democrática e Política Comparada. Revista de Ciências Sociais, v.42, n. 4, 1999. p. 577- 654.

RODRIGUES, Adriano. O acontecimento. In: TRAQUINA, Nelson. (org.). Jornalismo: Questões, teorias e 'estórias'. 1. ed. Lisboa:Vega, 1993. p. 27-33.

FOLHA DE SÃO PAULO. Supremo revoga a Lei de Imprensa. n 29.264, 1\%/5/ 2009.

TEIXEIRA, Ariosto. Entrevista concedida à autora deste trabalho. Brasília, 2008.

TUCHMAN, Gaye. A objetividade como ritual estratégico: uma análise das noções de objectividade dos jornalistas. In: TRAQUINA, Nelson. (org.). Jornalismo: Questões, teorias e 'estórias'. 1. ed. Lisboa: Vega, 1993. p.74-90.

VEJA, edição n. 1. São Paulo: Editora Abril, 11/09/1968. , edição n. 457. São Paulo: Editora Abril, 8/6/1977. , edição n. 974. São Paulo: Editora Abril, 6/5/1987. edição n. 1019. São Paulo: Editora Abril, 16/3/1988. edição n.1022. São Paulo: Editora Abril, 13/4/1988. edição n. 1023. São Paulo: Editora Abril, 20/4/1988. edição n. 1024. São Paulo: Editora Abril, 27/4/1988. , edição n. 1025. São Paulo: Editora Abril, 4/5/1988. edição n. 1027. São Paulo: Editora Abril, 18/5/1988. edição n.1034. São Paulo: Editora Abril, 6/6/1988. , edição n. 1037. São Paulo: Editora Abril, 20/7/1988. 
, edição n. 1049. São Paulo: Editora Abril, 12/10/1988.

VEJA, lançamento editorial. São Paulo: Editora Três, 1º/5/ 1976.

edição n. 582. São Paulo: Editora Três, 3/2/1988.

edição n. 583. São Paulo: Editora Três, 10/2/1988.

edição n. 586. São Paulo: Editora Três, 16/3/1988.

edição n. 588. São Paulo: Editora Três, 30/3/1988.

edição n. 595. São Paulo: Editora Três, 18/5/1988.

edição n. 597. São Paulo: Editora Três, 10/6/1988.

edição n. 599. São Paulo: Editora Três, 15/6/1988.

Recebido em: 30/7/2015

Aceito em: 5/8/2015

Endereço da autora:

Cândida Emília Borges Lemos candida.lemos@prof.una.br

Instituto de Comunicação e Artes do Centro Universitário UNA

Rua dos Goitacazes, 1.159 - Campus Barro Preto

CEP: 30190-051

Belo Horizonte, MG - Brasil 